\title{
HOSPITAL DISASTER RISK MANAGEMENT: THE CASE OF URMIA HOSPITALS
}

\author{
FARSHAD FAGHISOLOUK, REZA KHANI JAZANI*, SANAZ SOHRABIZADEH \\ Department of Health in Disasters and Emergencies, School of Health, Safety and Environment, Shahid Beheshti University of Medical \\ Sciences, Tehran, Iran. Email: rkhanijazani@gmail.com
}

Received: 11 November 2017, Revised and Accepted: 12 December 2017

\section{ABSTRACT}

Objective: This study has been conducted with the aim of assessing the risk management category and its status in hospital from the perspective of senior managers in Urmia hospitals considering the existing scientific gap and the importance of the issue for the health system and society.

Methods: This cross-sectional research was conducted in all 12 hospitals in Urmia. Participants in the research included 37 senior hospital managers. Data gathering instrument was a researcher-made questionnaire with Likert scale. Content validity and reliability of the tool (Cronbach's alpha coefficient) have been also measured in a similar study. This tool has been designed in two parts: Demographic specifications and items (44 questions). Kolmogorov-Smirnov, ANOVA one-way, independent t-test, and Spearman tests were used in SPSS 20 software for statistical analysis.

Results: The average of total score of all risk management components was equal to 3.0445, which is in moderate level. According to ANOVA one-way test, there was no significant relationship between the organizational status of managers and their education level with any of the risk management components. Furthermore, it was specified using independent t-test, there is no statistically significant relationship between gender and risk management components. It was specified using Pearson correlation test; there is a statistically significant relationship between gender and education level as well as individual's organizational status (p-value: 0.001 ).

Conclusion: Studied hospitals have suffered from the lack of risk management. There is not enough knowledge in this regard among senior hospital managers, and therefore, due to the importance of this issue, needed policies and programs should be provided to all hospital managers and needed supporting and education should be provided in regard to the implementation of risk management measures.

Keywords: Risk management, Disaster, Hospital, Urmia.

(c) 2018 The Authors. Published by Innovare Academic Sciences Pvt Ltd. This is an open access article under the CC BY license (http://creativecommons. org/licenses/by/4. 0/) DOI: http://dx.doi.org/10.22159/ajpcr.2018.v11i3.23625

\section{INTRODUCTION}

Organizations encounter with a wide range of hazards and risks and these risks are uncertain events that, if they occur, affect the organization's ability to achieve its purposes in undesirable manner [1] and potentially cause to damage individuals or organizations [2]. Therefore, it is necessary for organizations to identify their risks and implement programs to manage these risks, in regard to achieve their purposes, and therefore, identification and management of risk can be considered as one of the necessary approaches that are used to enhance and improve the effectiveness of organizations [1]. Risk management is a systematic process to identify, evaluate, prioritize risks, and adopt strategies to reduce risks and reach it to acceptable level [3-6]. Healthcare organizations are considered to be the most risky organizations of the world due to the nature of the work, structural, physical and technological complexities, and encounter with a great deal of risks in patient care and employees management [2].

Healthcare employees are always exposed to contagious diseases, chemical and biological poisons, carcinogens substances, and various radiations [7], and therefore, the issue of risk management in hospitals has been addressed and hospitals are required to form events and disasters risk assessment team in the comprehensive guideline for the accreditation of Iranian hospitals in 2016. Hospitals are susceptible to various events at any given time, and this important issue especially has more sensitivity in old hospitals and overcrowding for care services. Therefore, the attention of senior managers to preventive planning and create preparedness to encounter with risks is valuable investment that it is needed to be included in the agenda of hospitals management [8].

Systematic and effective risk management implementation through all parts of the hospital can have positive results and causes to reduce medical errors and improves the quality of service provision [9]. Moreover, this matter has caused hospitals employ people called risk managers. In many hospitals, senior managers do not have enough time to deal with risk management issues because of their busy work, and in many cases, there are resistances against risk management because of conflict in interests. Risk management is very complicated in hospitals because each hospital has its own unique policies, methods, and priorities [9].

The American Medical Association Statement in 2000 stated that between 44,000 and 98,000 Americans die each year as a result of medical errors. Retrospective studies in several countries have shown that between $2.9 \%$ and $16.6 \%$ of patients in hospitals experience one or more exposure to hazardous events, and in $4.5-20.8 \%$ of cases, these events have been caused them to die while about $50 \%$ of these risks have been predictable, which it matter indicates the importance of the issue of risk management in hospitals [10]. Another study has shown that senior managers' perception of risk is 1.4 more than ordinary employees and is 25.1 times more than departments' supervisors. Furthermore, $14.1 \%$ of employees have said that senior managers do not have clear understanding and image of risks related to patient care, and $15.8 \%$ believed that there is no appropriate communication flow in the hospital's chain of command on the topic of safety [11]. In the healthcare sector, there are clear evidences of the effect of managers on safety at workplace, but there are not enough articles and research on their attitudes and efforts to increase risk and safety management [12]. Therefore, this research has been conducted with the aim of assessing the risk management category and its status in hospital from the perspective of senior managers in Urmia hospitals considering the existing scientific gap and the importance of the issue for the health system and society. 


\section{METHODS}

This research is the cross-sectional (descriptive-analytic) that has been conducted in all 12 hospitals in Urmia, including governmental, private, and affiliated hospitals with the Social Security Organization and Armed Forces of Urmia.

Participants in the research were selected by census method and included all 37 senior managers of hospitals who worked in presidency, internal manager, treatment manager, and hospital nursing services manager. The data collection tool was a questionnaire in Likert scale and has been designed in five items method (very low, low, average, high, and very high) and in two sections: Demographic characteristics and items (44 questions), and has been used previously in conducted research by the men of Zaboli et al. [13] and Zarezade et al. [14]. The questionnaires were distributed among all senior managers of Orumieh hospitals during July and August 2017 and were collected by researcher after providing explanations about how the questionnaire should be completed that the responsiveness rate was $100 \%$. In this research, the validity of the questionnaire's content was confirmed by the opinion taking of three professors and experts in this field. Cronbach's alpha method was used to measure the reliability of the instrument that its calculation is based on the standard deviation of the questions. If this is more than 0.7, then, it can be said that the instrument is stable [15]. According to Table 1, the above coefficient amount has been presented in this research for each of the various risk management components that its overall average was $95 \%$. Kolmogorov-Smirnov, ANOVA oneway, and independent t-tests were used for statistical analysis and Spearman test was used for correlation between variables in SPSS 20 software.

\section{RESULTS}

Among the participants in the research, 30 persons were male $(12$ persons at the post of presidency, 13 persons were in the position of hospital management, and 5 persons were in the position of nursing services management) and 7 persons were female (nursing services management) (Table 2). Of these numbers, 7 persons have a diploma, 5 persons have a bachelor's degree, 14 have master degree, and 11 persons have Ph.D. degrees or are doctor. The level of education in females is more diploma (71.4\%) and then bachelor (28.6\%), respectively, and in males, from more to less, had included master (46.7\%), Ph.D. and

Table 1: Cronbach's alpha coefficient associated with risk management assessment components

\begin{tabular}{ll}
\hline Components & $\begin{array}{l}\text { Cronbach's alpha } \\
\text { coefficient }\end{array}$ \\
\hline $\begin{array}{l}\text { The level of recognition of managers from } \\
\text { risk management }\end{array}$ & 0.945 \\
$\begin{array}{l}\text { The status of the organization of risk } \\
\text { management }\end{array}$ & 0.949 \\
$\begin{array}{l}\text { The status of policies and procedures in the } \\
\text { field of risk management }\end{array}$ & 0.952 \\
$\begin{array}{l}\text { Risk management education status } \\
\text { Risk management position }\end{array}$ & 0.945 \\
$\begin{array}{l}\text { Monitoring the risk analysis, assessment, and } \\
\text { control }\end{array}$ & 0.949 \\
\hline
\end{tabular}

Table 2: Organizational status of individuals in the studied hospitals based on gender

\begin{tabular}{lll}
\hline Job & Gender & Frequency \\
\hline Hospital presidency & Male & 12 \\
Hospital manager & Male & 13 \\
Nursing manager & Male & 5 \\
& Woman & 7 \\
Total & & 37 \\
\hline
\end{tabular}

higher $(36.7 \%)$, bachelor $(10 \%)$, and then diploma (6.7\%). In terms of organizational status, men were in the level of manager of hospital with $43.3 \%$, hospital presidency $40 \%$, and $16.7 \%$ nursing services manager, respectively. Women have been also only in the status of nursing manager and they are not in other categories. Of all the studied hospitals, there were five governmental hospitals, four private hospitals, two military hospitals, and one hospital affiliated with the Social Security Organization.

The average of each of the risk management components was calculated based on the score of five that overall average of all components was equal to 3.0445 . The highest average score belonged to the risk management organizational status index (3.1542) and the lowest average score belonged to the status of policies and procedures in the area of risk management (2.8928) (Table 3).

In the purpose related to the rate of managers' recognition of risk management, the highest average score was related to being familiar with the concept of risk management in the hospital with average of 3.35. In the purpose related to the organization status of risk management, the highest average of scores is related to the organization of employees in the field of risk management by managers (3.32). In the purposes related to the status of policies and procedures in the area of risk management, the highest average was related to the availability of qualitative methods in the policies, written procedures, and methods about improving risk management.

In the purpose related to the status of risk management education, the highest average score was related to the facilities and services needed for risk management education (3.32), and in the purpose related to the risk management position, the highest average score was related to reporting and report taking in utilization in the risk management field (3.29). In the purpose related to monitoring the risk analysis, evaluation, and control, the highest average score is related to the reflection of the results of risk control activities to various units and departments (3.35).

In the Pearson correlation test, there was a statistically significant relationship between the level of education and gender kind (p-value: 0.001) and this relationship is 0.73 (Table 4). Furthermore, there was a statistically significant relationship between Pearson correlation between gender and organizational status of individuals $(\mathrm{p}=0.001)$ and this relationship was 0.69 (Table 4).

Table 3: The average of each component of the risk management assessment

\begin{tabular}{lll}
\hline Row & Components of the risk management & Average \\
\hline 1 & $\begin{array}{l}\text { The level of recognition of managers from risk } \\
\text { management }\end{array}$ & 3.0025 \\
2 & $\begin{array}{l}\text { The status of the organization of risk } \\
\text { management }\end{array}$ & 3.1542 \\
3 & $\begin{array}{l}\text { The status of policies and procedures in the } \\
\text { field of risk management }\end{array}$ & 2.8928 \\
4 & $\begin{array}{l}\text { Management education status of risk } \\
\text { management }\end{array}$ & 3.0828 \\
5 & $\begin{array}{l}\text { Position of risk management } \\
\text { Monitoring the risk analysis, assessment, and } \\
\text { Total }\end{array}$ & $\begin{array}{l}\text { control } \\
\text { n }\end{array}$ \\
\hline
\end{tabular}

Table 4: Pearson test for significant measurement of gender relationship with education level and organizational status

\begin{tabular}{llllll}
\hline \multirow{2}{*}{ Variables } & \multicolumn{2}{l}{ Organizational status } & & \multicolumn{2}{c}{ Education } \\
\cline { 2 - 3 } \cline { 5 - 6 } & $\boldsymbol{p}^{*}$ & Freedom degree & & $\boldsymbol{p}^{*}$ & Freedom degree \\
\hline Gender & 0.001 & 2 & 0.001 & 3 \\
\hline * & $20 n f i d e n c e$ & & &
\end{tabular}

*Confidence interval: (0.95) 
According to one-way ANOVA, there was no statistically significant relationship between the organizational status of managers and their education with any of the risk management components. Furthermore, using independent $\mathrm{t}$-test, there was no statistically significant relationship between gender and risk management components (Table 5).

\section{DISCUSSION}

Overall, the average of risk management score among senior managers of hospitals in Urmia was 3.0445, which is in average level. In another research conducted by Zaboli et al. [13] on the field of employee's knowledge rate of risk management in different parts of hospitals in Tehran, the overall average score of risk management assessment has been obtained (3.2) and has been assessed at an average level which is similar to the findings of the present research. Furthermore, in dimension of employee recognition level of risk management, the highest average score is related to the familiarity with concept of risk management (3.82), which is in line with the results of this research (3.35). In another research conducted by Zarezade et al. with the subject of risk management assessment at Shahid Rahnemoon Hospital in Yazd from nurses' perspectives, the level of employee recognition has been obtained from 5 score to 2.4, which had been in average level [14]. The obtained results of a research conducted by Habibi et al. entitled investigating risk management status in the radiology departments of hospitals in Isfahan showed that the risk management status is in the level of average to weak [7]. In another research, the risk management status of anesthesia - surgery in hospitals of Isfahan Medical Sciences University had been an average of 2.13 , which indicates the average risk management situation in those hospitals [16]. The results of this research are consistent with the present research. Therefore, it seems in most of the researchers conducted in the country that have been conducted to evaluate and analyze risk management in hospitals and medical centers; the obtained results indicate the average level is in the governing state on the risk management.

In a research that has investigated perceptual differences and diversity in crisis management, it has been concluded that managers in different organizations have different perceptions of crisis management, and this difference in perception based on demographic characteristics such as gender, management experience in times of crisis, the background of previous profession, and the current organizational status is not statistically significant [17]. These results are different from the findings of the present research. In another research, it has been specified that there is a significant difference between the average scores of crisis management components and gender [18], which also contradicts the results of this research. In total, by comparing the results of these researches with the present research, it can be concluded that the relationship between risk management category and demographic characteristics has different results and certain result cannot be obtained in this field.
According to the findings of this research that evaluated the risk management situation in hospitals at an medium level, it is suggested that safety, disasters, and events experts to be employed to increase the safety of personnel and patients in dealing with risks, as risk manager to assess, identify, and prevent from creating risk and to minimize their consequences and that hospitals have cadre planning with the backing of senior managers in this regard. It is also necessary to provide executives with the necessary training in the formulation and implementation of risk-coping programs to create a new attitude among them in this category.

\section{Research limitations}

The lack of adequate knowledge among senior managers of hospitals regarding disasters risk management was one of the research constraints that was devoted the time to educate them in the risk management field in hospitals and approaches available in this field prior presenting the questionnaire. The lack of time for senior managers of hospitals to allocate the time to interview and complete the questionnaires was one of the important constraints of the research, which we tried to overcome this constraint by determining the previous appointment and referral with coordination and at specified times.

\section{CONCLUSION}

It seems regardless of the importance of the issues related to risk management and identification of potential risks that there are especially in hospitals; unfortunately, the risk management situation in the studied hospitals is not favorable and risk management in most hospitals has had no particular in charge section and identifying and preventing or minimizing the risk occurrence possibility is not done through a scientific method. Although there is an attitude among hospital managers that risk management is important and leads to a threat to the health of patients and personnel, there is not enough knowledge among these managers that this matter is due to the lack of appropriate policies and provides comprehensive plans by the upstream institutions.

Finally, it seems that carrying out the risk management process in hospitals requires and belief in the process being carried out by senior managers and related policy-makers and working in group and participation among employees at all levels of the hospital. In addition, prioritizing, identifying, and preventing risks should be done taking into account the various dangers in the different departments of the hospital due to the difference in work done in these units, suggesting that performing this work in hospitals with other public and private organizations has a lot of complexities and differences in nature. Therefore, it is suggested to create a model to provide a risk management structure in hospitals of the country to identify, prevent, and control the risks by comparative study of other hospitals in the world, and also to develop different risk management standards for our country by studying and investigating successful organizations of health and care centers, in and out of the country.

Table 5: Independent ANOVA one-way and independent t-test for measuring the significant between variables of organizational status, education, and gender with risk management components

\begin{tabular}{|c|c|c|c|c|c|c|}
\hline \multirow[t]{3}{*}{ Risk management components } & \multicolumn{6}{|c|}{ Variables } \\
\hline & \multicolumn{2}{|c|}{ Organizational status } & \multicolumn{2}{|c|}{ Education } & \multicolumn{2}{|c|}{ Gender } \\
\hline & $p^{*}$ & Coefficient F & $p^{*}$ & Coefficient F & $p^{*}$ & Coefficient $\mathbf{F}$ \\
\hline The level of recognition of managers from risk management & 0.386 & 0.980 & 0.154 & 1.867 & 0.136 & 2.332 \\
\hline The status of the organization of risk management & 0.438 & 0.845 & 0.271 & 1.362 & 0.373 & 0.813 \\
\hline $\begin{array}{l}\text { The status of policies and procedures in the field of risk } \\
\text { management }\end{array}$ & 0.482 & 0.746 & 0.111 & 2.167 & 0.326 & 0.991 \\
\hline Position of risk management & 0.277 & 1.334 & 0.161 & 1.829 & 0.428 & 0.642 \\
\hline Monitoring the risk analysis, assessment, and control & 0.109 & 2.362 & 0.118 & 2.110 & 0.140 & 2.284 \\
\hline
\end{tabular}

*Confidence interval: $(0 / 95)$ 


\section{ACKNOWLEDGMENTS}

Thanks to all the senior managers of the hospitals in Urmia city for the cooperation, allocation of time, and information presentation.

\section{REFERENCES}

1. Marwick C, Davey P. Care bundles: The holy grail of infectious risk management in hospital? Curr Opin Infect Dis 2009;22:364-9.

2. Aufseeser-Weiss MR, Ondeck DA. Medication use risk management: Hospital meets home care. J Nurs Care Q 2001;15:50-7.

3. Berg HP. Risk management: Procedures, methods and experiences. Risk Manage 2010;1:79-95.

4. Stoneburner G, Goguen AY, Feringa A. Sp 800-30. Risk Management Guide for Information Technology Systems, Technical report. Gaithersburg: National Institute of Standards and Technology; 2002.

5. Karna KH, Sharma SA, Inamdar SH, Bhandari AN. Study and evaluation of medication errors in a tertiary care teaching hospital-a baseline study. Int J Pharm Sci 2012;4:587-93.

6. Singh SP, Rajender M. A prospective observational study on risk assessment of stemi patients at a tertiary care hospital. Int J Pharm Pharm Sci 2015;4:148-53.

7. Habibi E, Soleyman B, Nateghi R, Ruzbehani ML, Yarmohammadian $\mathrm{MH}$. Risk management in the department of radiology of shahid isfahan university hospitals. Health Inf Manage 2007;4:133-41.

8. Iran Ministry of Health and Medical Education. Comprehensive Hospital Accreditation Guide; 1395.
9. Buchholz SD. 'Quality is job 1'-new directions for medical risk management. J Healthcare Risk Manage 2000;20:34-38

10. Dückers M, Faber M, Cruijsberg J, Grol R, Schoonhoven L, Wensing M. Safety and risk management interventions in hospitals. Med Care Res Rev 2009;66:90s-119s

11. Singer SJ, Falwell A, Gaba DM, Baker LC. Patient safety climate in US hospitals: Variation by management level. Med Care 2008;46:1149-56.

12. Parand A, Dopson S, Renz A, Vincent C. The role of hospital managers in quality and patient safety: A systematic review. BMJ Open 2014;4:e005055.

13. Zaboli R, Karamali M, Rafati S. Evaluation of risk management situation in selected sections of Tehran hospitals. J Milit Med 2011;12:197-202.

14. Zarezade M, Abolhasani M, Eslami S, Salarikhah E, Bagheri F, Salmani E. Evaluation of risk management from the perspective of hospital nurses in Shahid Rahnemon Hospital. Occup Med Q J 2013;5:88-94.

15. Habibpour Gatabi K, Safari R. Comprehensive Manual for Using SPSS in Survey Researches; 2015.

16. Mousavi A, Asefzadeh S, Raeisi AR. Assessment of anesthesia-surgury risk management at hospitals of isfahan university of medical sciences, using ECRI institute standards in 2011. J Health Admin 2013;16:85-98.

17. Osilaja PD. Issues of Diversity in Crisis Management. California, America: University of La Verne; 2009.

18. Seyedin SH, Zaboli R, Malmoon Z, Rajabifard F. General hospital managers' perception regarding crisis management at Iran and Tehran university of medical sciences. J Hospital 2016;15:95-102. 